\title{
Design and implementation of EMI suppression filter for electronic commutation fan systems
}

\author{
Ching-Chun Chuang ${ }^{1}$, Chih-Chian Hua ${ }^{2}$, Chung-Wen Huang ${ }^{2}$, Chun-Jen Yao ${ }^{3 *}$ \\ ${ }^{1}$ Department of Computer Science and Information Engineering, National Formosa University, \\ No. 63, Wunhua Rd., Huwei Township, Yunlin 632, Taiwan (R.O.C), \\ ${ }^{2}$ Department of Electrical Engineering, National Yunlin University of Science and Technology, No. 123, University Rd., \\ Section 3, Douliu, Yunlin 640, Taiwan (R.O.C), \\ ${ }^{3}$ Department of Electronic and Computer Engineering, National Taiwan University of Science \\ and Technology, No. 43, Section 3, Keelung Rd., Taipei 106, Taiwan (R.O.C),
}

E-mail: "austincc@nfu.edu.tw,huacc@yuntech.edu.tw,wenhung@yuntech.edu.tw,alanyao@mail.ntust.edu.tw

\begin{abstract}
An electronically commutated fan has a complex digital control mode compare to the conventional alternating current fans. Since a serious electromagnetic compatibility situation was produced in the electronic commutation fan system, the filter circuit of a fan system and its mechanical design was significantly important. Because the digital control strategy for an electronically commutated fan was used to reduce the component of the EMI filter so the suppression of conducted and radiated electromagnetic interference will be discussed in this fan system. Moreover, the fan system can be combined with the mechanical design for getting over a series of issues of radiated electromagnetic interference. Thus, fig. 1 reveals that a single-phase BLDC motor driver schematic diagram. Eventually, a cause that electromagnetic interference was produced from the electronically commutated fan will be analyzed and its suppression strategy also provided in this paper. The experiment verification for the electronically commutated fan will be made available to the public.
\end{abstract}

Keywords : Electronically commutated fan, Electromagnetic compatibility, Digital control mode

\section{Introduction}

The electronic communication fan that combines the frequency conversion function, and the power transistors for frequency modulation to achieve speed control. Because of the higher speed, the motor output efficiency is improved. The Single-Phase BLDC motor system is driven by AC power supply. A DC motor is used inside of this system, so the friction loss is reduced. Thus, the advantages of AC and DC fans are combined to improve the efficiency and life of the overall electronic commutation fan. Fig. 1 show a commercial electronic commutation fan product architecture [1]. A number of switch devices were switched at high speed, and the

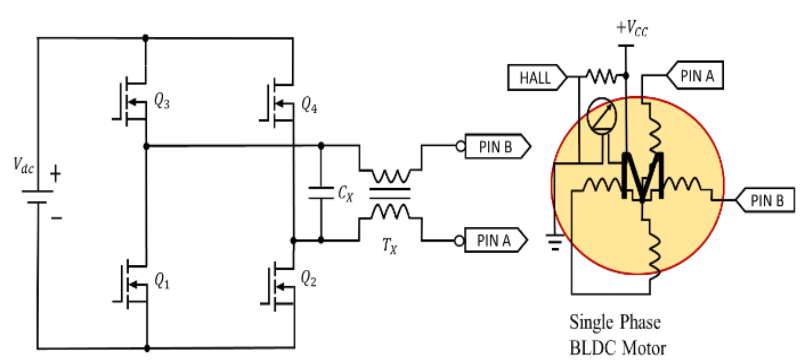

Fig. 1. Single-Phase BLDC motor driver schematic diagram voltage and current are changes at the same time. The result not only cause more serious electromagnetic interference problems [2] [3] [4], but also affected the electromagnetic tolerance of the internal controller. 
Therefore, an attention has to consider in the production design for passing relevant electromagnetic compatibility certification.

\section{EMI Standard for Electronic Communication System}

Generally speaking, Electromagnetic Compatibility (EMC) is divided into two types of tests: Electromagnetic Interference (EMI) and Electromagnetic Susceptibility (EMS) [5][6]. Electromagnetic interference testing refers to measure of the intensity of conductive interference and radiant interference while the electronics device is normal operated under testing. The purpose of electromagnetic interference suppression design is to reduce the intensity of noise generated by the electronics device under testing, and it was not to affect other electronic products in the test environment. On the contrary, the purpose of electromagnetic tolerance is to prevent the DUT from being interfered with by other electronic products in the environment during operations

There are international standards for the electromagnetic interference law of electronic communication fans, which can refer to the European regulations EN 55011, the United States FCC PART 18 and the domestic CNS 13803. Among them, there are two different limit values of class A and class B based on this product are used in commercial or residential households. However, the products analysis in this paper will be used in information products since Europe is the main market. So, the information products for European standards will be adopted. Class B electromagnetic interference standard in EN55022, EN55022[7] and EN55011[8] were the same Class B electromagnetic interference test standard.

\section{EMI Suppression and Analysis of Electronic Communication System}

\subsection{Conduction EMI measurement}

To measure the noise values of the live wire (Line, L) and neutral wire (Neutral, N) after a connection of the LISN. The measure results are shown in Fig. 2 and Fig. 3. Observing the two figures, it can be seen that the test value without any filter and other countermeasures far exceeds the standard limit value.

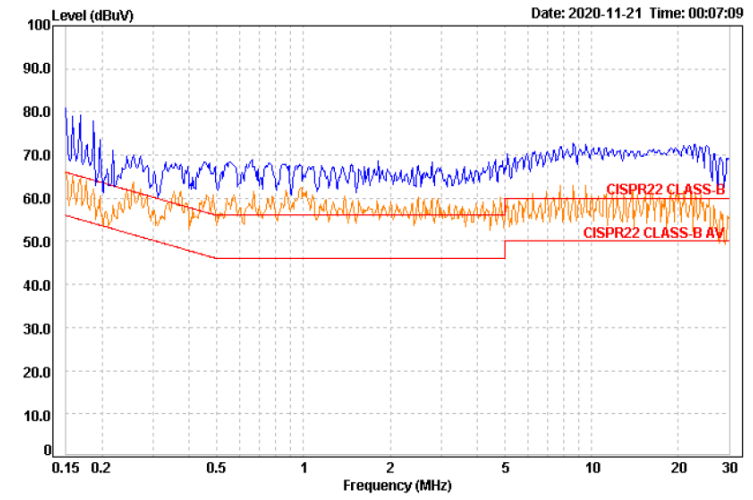

Fig. 2 EMI testing of L Phase conductivity

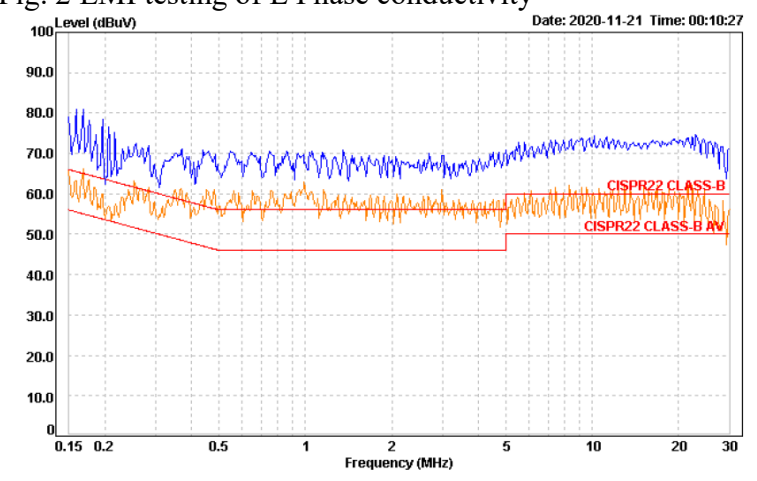

Fig. 3 EMI testing of N Phase conductivity

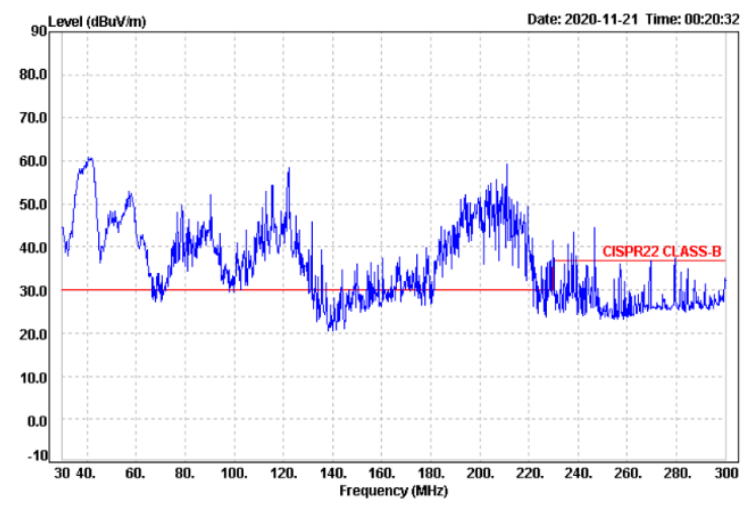

Fig. 4 The vertical polarity test of radiation EMI

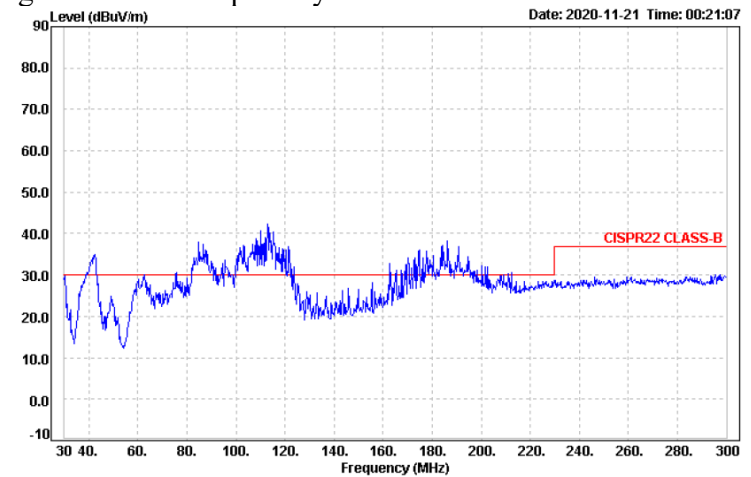

Fig. 5 The horizontal polarity test of radiation EMI

(C) The 2021 International Conference on Artificial Life and Robotics (ICAROB2021), January 21 to 24, 2021 


\subsection{Radiation EMI measurement}

According to section, the noise measurement of the EUT was received through the antenna under two different polarities, vertical and polar. The actual test diagrams are shown in Figure 4 and Figure 5. It can also be seen that the noise radiated through space is very serious.

3.3 The Suppression Strategy for Conduction EMI and Radiation EMI

\subsubsection{A Strategy of Conduction EMI}

Conducted EMI is mainly used to measure the noise transmitted by the power line through LISN, so the main suppression method is to add an EMI filter to the power line [13]. However, it can be seen that a multi-stage filter with grounding is required to have a wider suppression range from Fig. 2. In this paper, the space of the DUT is limited, and there is no ground wire architecture. The input EMI filter architecture is adopted in the electronic commutation fan systems. The differential mode inductance is $100 \mathrm{uH}$, the $\mathrm{X}$ capacitor is $0.1 \mathrm{uF}$, and the common mode inductance is $20 \mathrm{mH}$. Fig. 6 and Fig. 7 show the actual test patterns after adding the input EMI filter and other countermeasures to the EUT internal circuit.

$$
\text { Attenuation }=10 \log \left(\frac{N \times \delta \times f_{c}}{f_{m}}\right)
$$

where $\mathrm{N}$ is harmonic number

$\delta$ is spread spectrum

$f_{c}$ is switching frequency

$f_{m}$ is frequency modulation

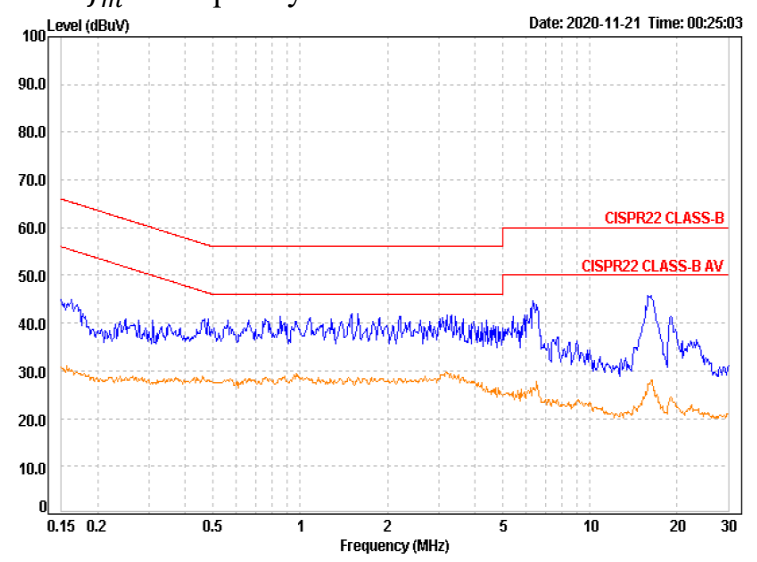

Fig.6 EMI testing of L Phase conductivity after suppression

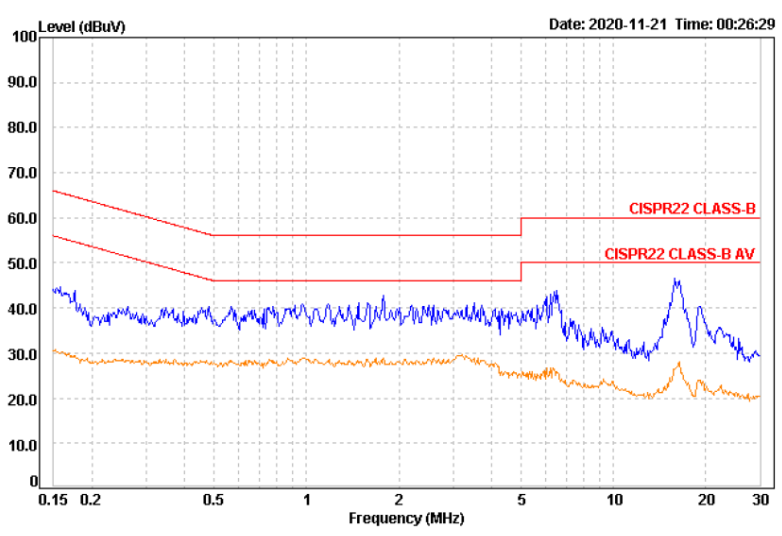

Fig.7 EMI testing of $\mathrm{N}$ Phase conductivity after suppression

\subsubsection{A Strategy of Radiation EMI}

In order to improve the radiation problem between the circuit output and the motor, an output EMI filter design is need in the electronic commutation fan systems. The common mode inductance is $0.95 \mathrm{mH}$ and the $\mathrm{X}$ capacitor is $4700 \mathrm{pF}$.

The EUT in this paper has two specifications, namely plastic fan blades and metal fan blades. Among them, the series of metal fan blades have the most serious radiated EMI problem. The noise generated by the drive motor will provide a path to the metal fan blade through the metal shaft, which will cause a serious antenna effect. Therefore, an insulating part will be added to the mechanism part, as shown in Fig. 8, which not only saves the cost of motor manufacturing but also greatly improves the problem of radiated EMI. Fig. 9 and Fig. 10 show the actual test patterns after EUT suppression.

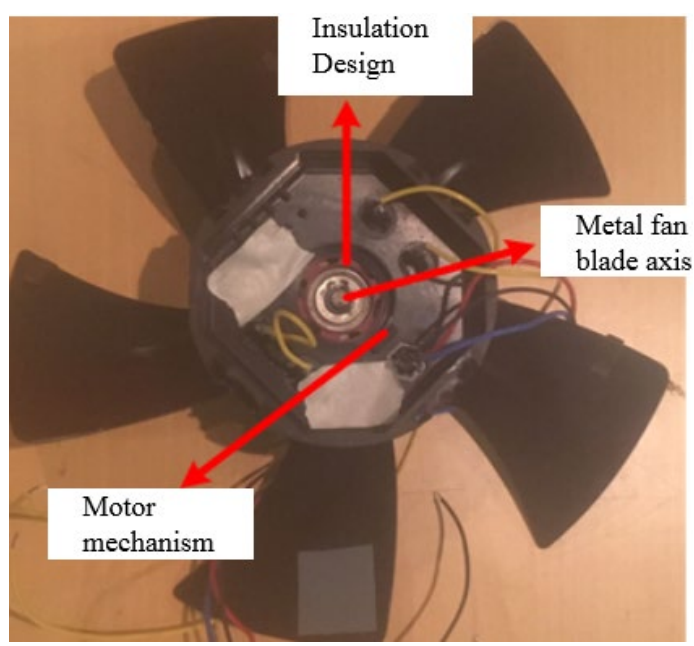

Fig. 8 A strategy for motor shaft and mechanism insulation design 


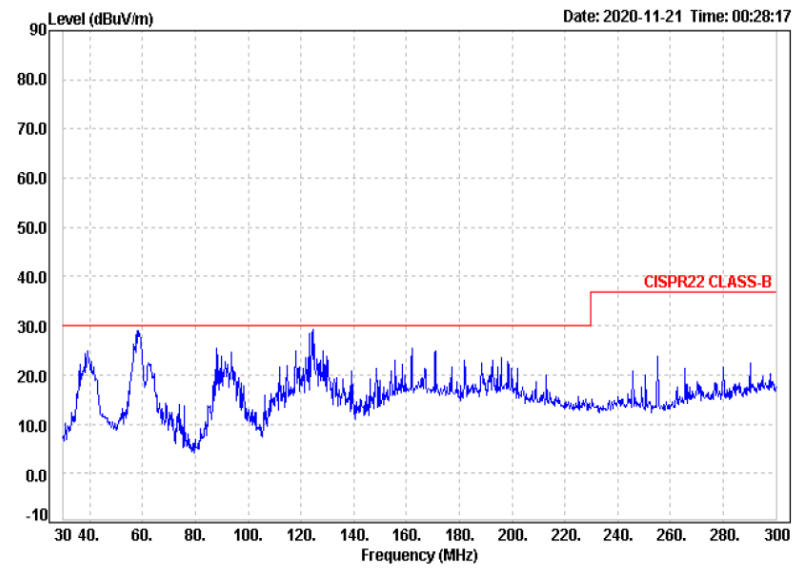

Fig.9 The vertical polarity test of radiation EMI after suppression

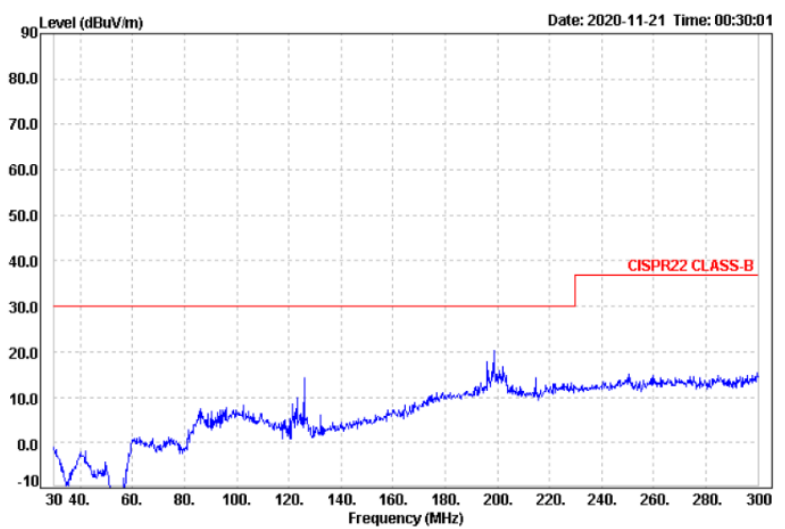

Fig.10 The horizontal polarity test of radiation EMI after suppression

\section{Conclusion}

This paper proposed an electronic commutation fan that is to perform the actual electromagnetic interference certification process for the EUT. The suppression of conductive EMI and radiate EMI was discussed, and a digital control system was to reduce the EMI filter components in this research. Meanwhile, it combines the mechanism to improve the design to overcome an issue that the system without grounding was operated that causes a serious radiated EMI problem. This method can not only be applied to this product, but also produced the similar effect for the other relative products. The goal that saves time and cost will be implemented after a successful certification of the subsequent relative products

\section{References}

1. S. Chen, T. A. Lipo and D. Fitzgerald, "Measurement and Analysis of Induction Motor Bearing Currents in PWM Inverter Drives", IEEE PES Summer Meeting, July 1995.

2. J. Erdman, R. J. Kerkman, D. Schegel and G. Skibinski, "Effect of PWM Inverters on AC Motor Bearing Currents and Shaft Voltages", APEC '95, vol. I, pp. 24-33, Mar. 1995.

3. Henry W. Ott, "Noise Reduction Techniques in Electronic Systems," John Wiley \& Sons, 1988.

4. C. R. Paul, "Introduction to Electromagnetic Compatibility," John Wiley \& Sons, 1992

5. EN 55022, Information Technology Equipment Radio Disturbance Characteristics - Limits and Methods of Measurement, 2010.

6. EN 55011, Industrial, Scientific and Medical Radiofrequency Equipment - Radio Disturbance Characteristics - Limits and Methods of Measurement, 1998.

7. S. Ogasawara, H. Akagi, "Analysis and Reduction of EMI Conducted by a PWM Inverter-fed AC Motor Drive System Having Long Power Cables," IEEE Power Electronics Specialists Conference, Vol. 2, pp. 18-23, 2000.

8. M. L. Heldwein, T. Nussbaumer, F. Beck and J. W. Kolar, "Novel Three-phase CM/DM Conducted Emissions Separator," IEEE Appl. Power Electron. Conf. Expo., pp. 797-802, March 2005.

9. R. L. Ozenbaugh, EMI Filter Design, Marcel Dekker, New York, 1996.

10. J. Kim, P. Jun, J. Kim, "Dithered Timing Spread Spectrum Clock Generation for Reduction of Electromagnetic Radiated Emission from Highspeed Digital System," In Proc., IEEE Int. Symp., Electromagn. Compat., pp 413-418, 2002.

11. Hardin, Fessler and Bush, "A Study of the Interference Potential of Spread Spectrum Clock Generation Techniques," IEEE International Symposium on EMC, August 1995.

12. A. Santolaria, J. Balcells, D. Gonzalez, J. Gago, and S. D. Gil,"EMI Reduction in Switched Power Converters by Means of Spread Spectrum Modulation Techniques," Power Electronics Specialists Conference, 2004. PESC 04. 2004 IEEE 35th Annual, vol. 1, pp. 292 - 296, June 2004. 